\title{
Features of operation of the grid connected photovoltaic power station with a capacity of $10 \mathrm{~kW}$
}

\author{
Isroil Yuldoshev ${ }^{1}$, Sanjar Shoguchkarov ${ }^{2}$, Tulqin Jamolov ${ }^{1}$, Shakhnoza Rustamova ${ }^{1}$ \\ ${ }^{1}$ Tashkent State Technical University, Department of Alternative energy sources, \\ Universitet -2, Tashkent, 100095, Uzbekistan \\ ${ }^{2}$ Physical-Technical Institute of SPA "Physics-Sun" of Academy of Sciences of RUz, \\ Chingiz Aitmatov - 2B, Tashkent, 100084, Uzbekistan
}

\begin{abstract}
Photovoltaic power station (PPS) operating function (without redundancy) with a nominal capacity of $10 \mathrm{~kW}$ connected to the low voltage electrical network established by "Zhejiang Chint Electrics Co Ltd" (PRC) under Tashkent conditions is defined. Operation parameters and characteristics of the PPS and parameters at the output of the network inverter are given. The deviations of voltage of each phase from the standard nominal voltage at the point of electric network transmission are studied. The analysis of the results of the evaluation of the power generation of the PPS for the conditions of clear weather and clear cloudiness was carried out. According to the monitoring data for the winter period is $2211,5 \mathrm{~kW} \cdot \mathrm{h}$. The problems of PPS connected to the lowvoltage network, connected to the loss of electric power with the account of influence of external factors and reliability of stable voltage and frequency in a permissible range are revealed.
\end{abstract}

\section{Introduction}

Energy shortages can be partially filled in many countries, including Uzbekistan, by using renewable sources of energy which are environmentally sustainable and affordable to consumers. In this regard it is advisable to use solar energy to produce electricity on an industrial scale, considering the substantial potential of solar energy in Uzbekistan. This is verified by the development and prospective photovoltaic solar station (PPS) programs, both abroad and in Uzbekistan [1-3].

The advancement of solar energy in Uzbekistan will undoubtedly contribute to addressing the country's energy security, social problems, environmental stability and improving the quality of life of the population. Unfortunately, the share of electricity generated in Uzbekistan using solar energy does not exceed 1 percent. The main obstacle to the wide introduction of solar energy is the lack of incentive measures for the population and industrial consumers, typical for China, Germany, Japan, 
Spain and the United States, and as a result, high capital investments, which fully fall on the shoulders of the consumer. Another significant problem is the lack of enterprises for serial production of photovoltaic converters, panels and component equipment based on modern technologies [4].

\section{Method}

The development of technical profiles for solar photovoltaic stations based on higher education institutions creates opportunity for students and researchers to collect experimental data on the functioning of stations, evaluating potential technological solutions. Using analytical measurement methods with the aid of programs, monitoring and control of photovoltaic battery development parameters, elimination of photovoltaic characteristics, their study according to meteorological parameters.

\section{Results and discussion}

A $10 \mathrm{~kW}$ power plant was constructed at the Heliopolygon of the Power Engineering Faculty of Tashkent State Technical University on the initiative of "Zhejiang Chint Electrics Co Ltd" and small enterprise "Chint Distribution Uzbekistan" (Fig. 1), and a scientific and educational laboratory "Inspection of electrical devices and creative control of their control and measuring mode" was developed.

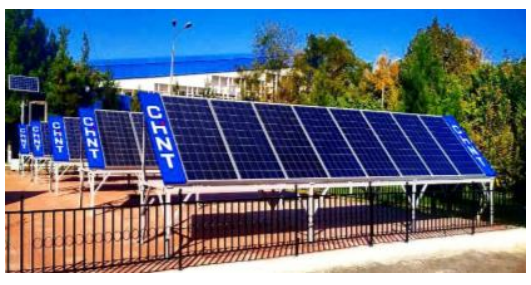

Fig.1. Solar photovoltaic station with capacity of $10 \mathrm{~kW}$ connected to low voltage network of the Faculty of Power Engineering

PPS consists of 40 PVB with seasonal orientation supporting structures to the south, three-phase network inverter with a capacity of $10 \mathrm{~kW}$, the panel inside which is located: three-phase electrical meter, automatic input-output switches, electrical cables.

PVB with a rated power of 270 $\mathrm{W}$ is 60 solar cells (SC) connected in series on the basis of polycrystalline silicon. The main parameters of PVB are presented at the website [5].

PPS consists of 2 parallel groups of PVBs electrically connected to each other, each containing 20 batteries connected in series. PPS is placed at an angle of 460 in the south direction. However, it is also worth considering the seasonal change in the angle of incidence of solar radiation. For each latitude, in which the region is located, there is an optimal angle of inclination of the PVB installation. The PVB rises above the Earth's level to create space for free air circulation. The distance between the horizontal plane and the $P V B$ is greater than $\geq 100 \mathrm{~cm}$.

The article addresses issues relating to optimum PPS configuration and coordination of components and equipment with electrical low voltage network.

The distance between the two rows when mounting the PPS is of great importance for a PPS which is not fitted with a tracking system and 
which maintains a static location throughout the year. The greater the distance between the rows, the less likely it is that the first row will be shaded above the horizon at a low altitude of the Sun, thereby ensuring reliable electricity generation and transmission to the grid. At the same time, an increase in this distance leads to an increase in the area occupied by the PPS; therefore, finding the maximum and minimum values of this distance contributes to an increase in the average annual value of the PPS efficiency.
Calculations have been made to find the optimal distance between the rows of PVB.

$$
d=S_{1}+S_{2}=\frac{L \sin (\alpha+\beta)}{\sin \beta}
$$

where $\alpha$ is the angle of the Sun's height above the horizon; $\beta$ is the angle of inclination of the PVB to the horizon; $d$ is the optimal distance between the PVB rows; $\mathrm{L}$ is the length of the PVB; $\mathrm{S}_{1}$ is the projection of the PVB length; $\mathrm{S}_{2}$ is the projection of the line of the solar radiation angle of incidence.

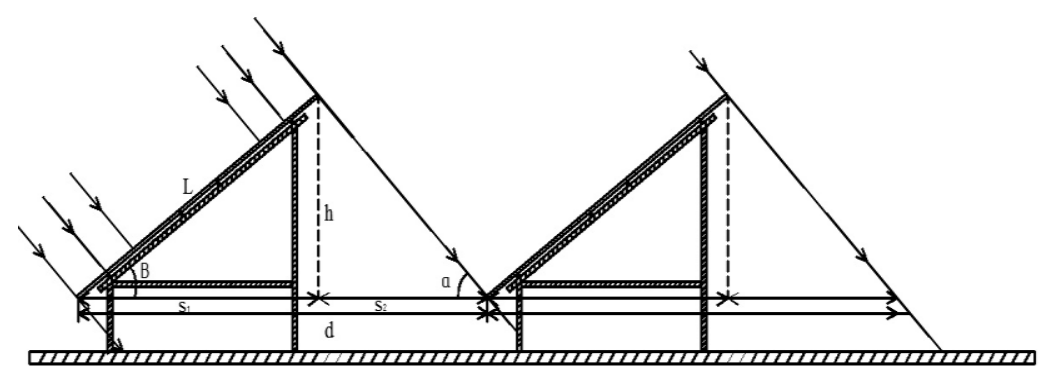

Fig.2. Determining the optimal distance between the rows of PVB

using formula (2) and the Sun Facts program, we will determine the duration of sunny days per day and the value of the Sun's elevation angle above the horizon $(\alpha)$ on June 22 and December 22, 2019 at 12:22 hours. According to the calculation results for June 22, the angle of the Sun's altitude above the horizon was $\alpha \sim 72,1^{\circ}$ and the duration of sunny days per day was the maximum of 15 hours, 10 minutes. $10 \mathrm{sec}$. The minimum values of the angle of the Sun's altitude above the horizon and the duration of solar days per day on 22 December 2019 were $\alpha=25,2^{0}$ and the day's length was 9 hours, 11 minutes and 12 seconds.

$$
\mathrm{T}_{\text {c.c }}=\frac{2}{15} \arccos \left(-\tan \varphi^{0} \tan \delta^{0}\right)
$$

were $\varphi^{0}$ - is the northern latitude of the terrain; $\delta^{0}$ - the declination angle of the Sun for a given day.

Let the raw data be:

If $L=165 \mathrm{~cm} ; \quad \alpha_{\min }=25,2^{0}$; $\alpha_{\max }=72,1^{\circ} ; \beta=46^{\circ}$, we have still conducted experimental studies to measure the length of the PVB shadow on June 22 nd and December

22 nd 2019 at 12:22 hours. The values of the minimum and maximum distance between the rows of PVB with a fixed location on the support structure are given in Table 1. 
Table 1. The values of the minimum and maximum distance between the rows of PVB with a fixed location on the support structure

\begin{tabular}{|c|c|c|c|c|}
\hline Date & \multirow{2}{\text{Ti}}{$\begin{array}{c}\text { Lift } \\
\text { me }\end{array}$} & $\begin{array}{c}\text { heig } \\
\text { ht, } \\
\mathbf{m}\end{array}$ & $\begin{array}{c}\text { Calcul } \\
\text { ation }\end{array}$ & $\begin{array}{c}\text { Shado } \\
\mathbf{w} \\
\text { length, } \\
\text { Expert } \\
\text {. }\end{array}$ \\
\hline $\begin{array}{c}22 \\
\text { Decem } \\
\text { ber }\end{array}$ & $\begin{array}{c}12: \\
22\end{array}$ & 2,03 & 3,66 & 3,72 \\
\hline $\begin{array}{c}22 \\
\text { June }\end{array}$ & $\begin{array}{c}12: \\
22\end{array}$ & 2,03 & 1,52 & 1,55 \\
\hline
\end{tabular}

Therefore, Table 1 shows that the value of the optimal distance between the PVB rows, measured and calculated using the formula (1), differ slightly $\sim 2-2,5 \%$. According to the obtained results, it can be concluded that the proposed measurement technique and calculation of the optimal distance provide high accuracy.

It is possible to draw a conclusion that at stationary placing of PVB, when an angle of slope is equal to value of northern latitude of the terrain, it is necessary to consider distance between rows of PVB. If at designing not to consider optimum distance between rows of PVB, then increase of distance form shading of the bottom sites of the following rows, accordingly leads to decrease of efficiency of PVB and the occupied superfluous area of the Earth. In the first case, the maximum power point of the shaded PPS is shifted to the negative voltage zone and opens a bypass diode, which is connected in parallel to each battery to prevent the shift of the operating point of the battery in the energy consumption zone and, as a consequence, failure of the PPS.

In addition, a majority of power grids are unable to cope with the excessive supply of electricity generated by a photovoltaic network. The generation of electricity from renewable energy sources is intermittent. Therefore, integration of PPS into the power system without damage to the quality of electric power is a more complicated task [69].

Electricity quality means the degree to which the voltage and frequency in the grid correspond to their normalized values. Decrease in power quality is defined as any power problem that manifests itself in deviations in voltage, current and/or frequency that result in failure and/or malfunction of end user equipment. Indicators of electric power quality related to slow changes of electric power supply voltage are negative $\delta \mathrm{U}$ ${ }_{(-)}$and positive $\delta U_{(+)}$deviations of electric power supply voltage at the point of electric power transmission from the nominal agreed value, $\%$ :

$$
\begin{gathered}
\delta U_{(-)}=\left[1-\frac{U_{m(-)}}{U_{0}}\right] \cdot 100 \% \\
\delta U_{(+)}=\left[1-\frac{U_{m(+)}}{U_{0}}\right] \cdot 100 \%
\end{gathered}
$$

where $\mathrm{U}_{\mathrm{m}(-),} \mathrm{U}_{-\mathrm{m}(+)}$ - supply voltage values, smaller $\mathrm{U}_{0}$ and larger $\mathrm{U}_{0}$, respectively, averaged in the time interval of $10 \mathrm{~min}$ according to the requirements of GOST 30804.4.30.

According to the indications, the quality of electric power is set by the following standards: positive and negative voltage deviations at the point of electric power transmission should not exceed $10 \%$ of the nominal or agreed voltage value [1011].

Measurements of operational parameters of $10 \mathrm{~kW}$ network PPS were carried out during daytime at Heliopolygon of Tashkent State Technical University on 26.12.2019 and 07.01.2020. Meteorological 
conditions 26.12.2019: cloudless sky, clear, air temperature $8 \div 14^{0} \mathrm{C}$, wind speed $1 \pm 5 \mathrm{~m} / \mathrm{s}$, humidity $21 \div 48 \%$, and average value of solar radiation flux density $\sim 668 \mathrm{~W} / \mathrm{m}^{2}$. Readings of meteorological devices, operational parameters of PPS and values of low voltage characteristics in electric networks with the help of three-phase electric meter were taken every 20 minutes, the Initial countdown time corresponds to $9 \mathrm{am}$.

In Fig. 3 presents the results of measuring the dependence of voltage deviation of each phase on the standard nominal voltage at the point of transmission of electrical energy.

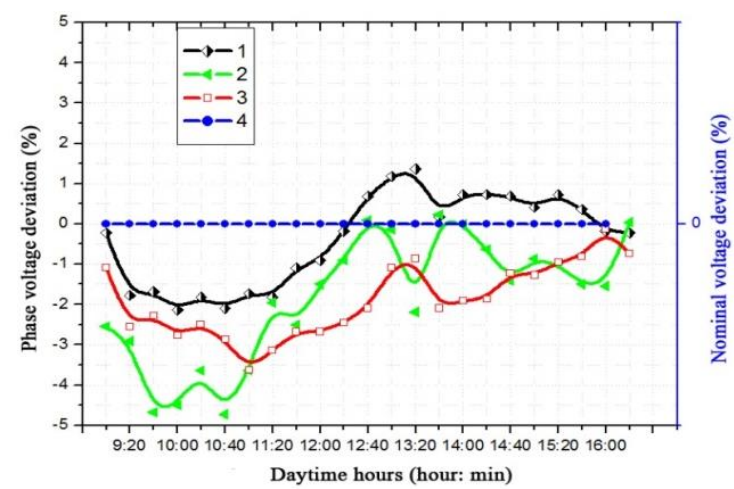

Fig.3. Dependence of the voltage deviation of each phase and the deviation of the nominal voltage from the day time of day (26.12.2019).

1-First phase voltage deviation; 2- second phase voltage deviation; 3 - third phase voltage deviation; 4- rated voltage deviation.

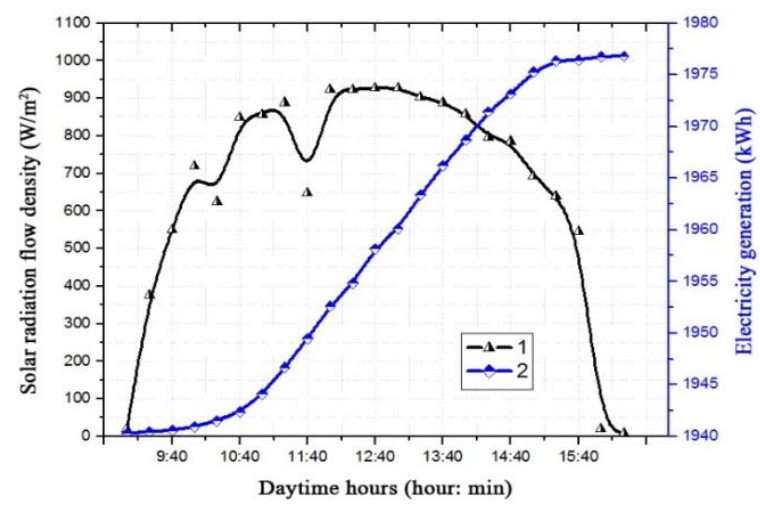

Fig.4. Dependence of the solar radiation flow and electricity production of the PPS on the time of day (26.12.2019)

1-dependence of solar radiation flux density on daytime; 2 -generation of PPS electricity from daytime.

Analyzing Fig. 3, it can be assumed that the voltage variation at the point of transmission of electrical energy in each step relative to the normal 
nominal voltage depends on the magnitude of the rise in loads in the local electrical networks. It can be seen that the deviation of voltage of each phase rushes to the nominal value of $\mathrm{U}_{0}$ at clear weather with declining loads in the network, and then the deviation value of each phase increasing be higher than $\mathrm{U}_{0}$.

The interval between $\delta U_{(-)}$and $\delta U_{(+)}$is $-4,7 \div 1,3$ percent, according to the tests.

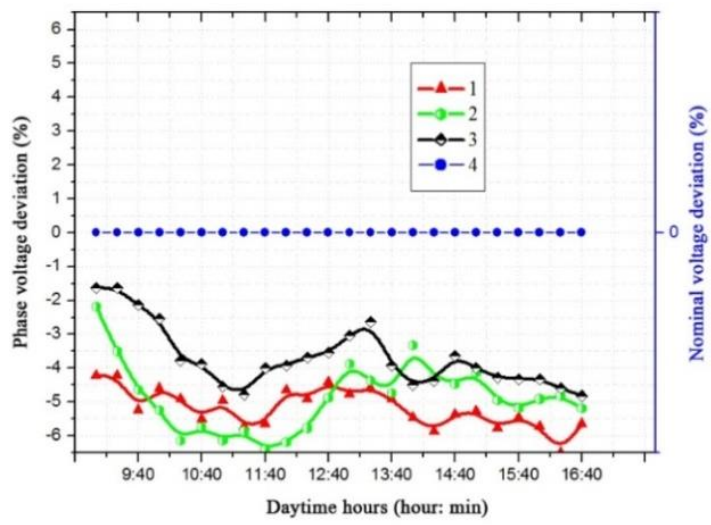

Fig.5. Dependence of the voltage deviation of each phase and the deviation of the nominal voltage from the day time of day (07.01.2020).

1- first phase voltage deviation; 2- second phase voltage deviation;

3- third phase voltage deviation; 4- rated voltage deviation.

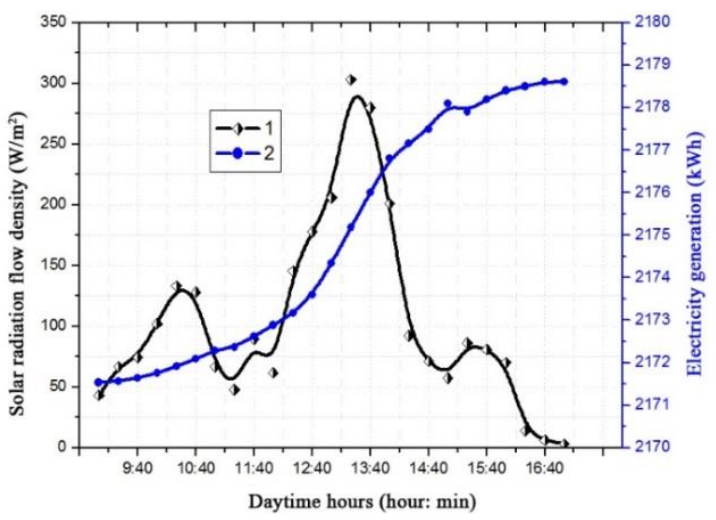

Fig.6. Dependence of solar radiation flow and electricity production of PPS on daytime (07.01.2020)

1-dependence of solar radiation flux density on the day time of day;

2 -generation of PPS electricity from the daytime. 
According to the monitoring data (Fig.4) on 26.12.2019, the grid PPS's power generation was $\sim 35,5 \mathrm{~kW} \cdot \mathrm{h}$. At fig. 6-7 present similar experimental findings to those reported at 07.01.2020. Meteorological conditions 07.01.2020: persistent cloudiness, air temperature $1 \div 4^{0} \mathrm{C}$, wind speed $\sim 0,5$ $\mathrm{m} / \mathrm{s}$, humidity $75-89 \%$, average density of solar flux $\sim 103 \mathrm{~W} / \mathrm{m}^{2}$. It is understood (Fig.5) that with a decrease in ambient temperature, the load consumed increases in the local electrical network, respectively, resulting in a significant decrease in the voltage deviation of each step from day time. At the point of the low voltage network, sharp fluctuations of positive and negative voltage differences will lead to a change of the normalized frequency value of 50 $\pm 0,2 \mathrm{~Hz}$. The interval between $\delta U_{(-)}$is $-6,5 \div-1,5$ percent, according to the results. The indication (Fig.6) on 26.12.2019 on the electric power generation by the grid PPS was $\sim 7$ $\mathrm{kW} \cdot \mathrm{h}$.

\section{Conclusion}

The following factors may pose problems in the operation of a solar photovoltaic plant connected to the low voltage network:

- The conversion efficiency of solar cells is still low and operating conditions differ considerably from standard ones (AM 1.5, $1000 \mathrm{~W} / \mathrm{m}^{2}$ solar flux density, $25^{\circ} \mathrm{C}$ solar cell temperature) [12-14];

- Lack of PPS solar tracking system. Usually, high-power PPS s is not equipped with $\mathrm{PB}$ orientation mechanisms taking into account seasonal variations;

- Extreme temperature conditions leading to a decrease in the power and efficiency of photovoltaic systems up to 40 percent in the summer months of the year [15];

- Relatively high atmospheric pollution by solid and gaseous particles, which leads to a decrease in the power of the PPS, as well as ice, frost and PVB [16,17];

- Losses at conversion of direct current into variable. The efficiency of network inverters is not stable and depends on the power of solar energy flow. At low density of solar radiation flow the network inverter may switch off;

- The quality of electrical energy generated by power plants based on PPS should meet the requirements of GOST 32144-2013;

- Not accurate design at installation of PPS can lead to formation of partial shading between PPS rows, which cause a decrease in efficiency and some cases of PPS failure.

\section{References}

1. K.K. Zaynutdinova Solar Energy Marketing in Uzbekistan. Monograph. Publishing house "Fan" of the Academy of Sciences of Uzbekistan. P.-186 (2011)

2. Tursunov, M.N.; Yuldoshev, I.A.; Shoguchkarov, S.K. Photovoltaic power stations, integration into the low-voltage electric network in the rural regions // "Use of the renewable energy sources: new research, technologies and innovative approaches". Materials of the conference of SPA "Physics-Sun" 2526 September. C. 43-46 (2018)

3. I.A. Yuldoshev, K.K. Tashmatov, E.B. Saitov, Bernd Wurl. Introduction and operation of the solar photovoltaic station integrated with the local electrical network // Geliotekhnika, 4. 59-62 (2017) 
4. I.A. Yuldoshev, Z.I. Zhuraeva, S.K. Shoguchkarov, S.S. Mahmudov Peculiarities of operation of solar photovoltaic station connected with local network of Islam Karimov TSTU // "Modern problems of renewable energy". Collection of materials of the Republican scientific-practical conference.18-19 May. Karshi pp.102-104 (2018)

5. www.chint.net (date of address:12.03.2020)

6. Kulkarni and Shingare A review on power quality challenges in renewable energy grid integration 1573-1574-1575 // International Journal of Current Engineering and Technology, 6(5) (2016)

7. Liu H., Jin L., Le D., and Chowdhury A. Impact of high penetration of solar photovoltaic generation on power system small signal stability, II in International Conference on Power System Technology (POWERCON), pp. 1-7. (2010)

8.A. Almeida, L. Moreira, J. Delgado (2013), Power Quality Problems and New Solutions, ISR Department of Electrical and Computer Engineering University of Coimbra, Vol. 3030290, pp. 1-9 Coimbra, Portugal, (2014)

9. Sandhu M., Thakur T. Issues, Challenges, Causes, Impacts and Utilization of Renewable Energy Sources Grid Integration. International Journal of Engineering Research and Applications, Vol. 4, pp. 636-643 (2014)

10. GOST 32144-2013 Electric power quality standards in general purpose power supply systems (2013) 11. GOST 30804.4.30.-2013 (IEC 61000-4-30:2008) Electric energy. Compatibility of technical means electromagnetic. Methods of measuring quality indicators of electric energy (Interstate Standard) ( 2013)

12. Yuldoshev, I.A., Shoguchkarov, S.K., Kudratov, A.R., Jamolov, T.R. A Study of the Parameters of a Combined Photo-Thermoelectric Installation under Field Conditions // Applied Solar Energy V.56. No. 2. pp. 125-130

13. Singh, P., Ravindra, N. Temperature dependence of solar cell performance - an analysis. Sol. Energ. Mat. Sol. Vol. 101, pp.36-45 (2012)

14. Emery, K., Burdick, J., Caiyem, Y., Dunlavy, D., Field, H., Kroposki, B., Moriarty, T., Ottoson, L., Rummel, S., Strand, T., Wanlass, M.W. Temperature dependence of photovoltaic cells, modules and systems. Photovolt. Spec. Conf. (PVSC), pp.1275-1278 (1996)

15. M.N. Tursunov, V.G. Dyskin, I.A. Yuldoshev, B.M. Turdiev Influence of the convective heat exchange on the solar photovoltaic battery temperature. Applied Solar Energy. V. 50. No 4, pp. 236-237

16. M. N. Tursunov, V.G. Dyskin, I.A. Yuldashev, Kh. Sobirov, Park Jeong Hwoan. A Criterion of Contamination of the Glass Surface of Photovoltaic Batteries // Applied Solar Energy.V.51. pp. 163-164 (2015)

17. Nurhasliza Hashim, M.N. Mohammed, Rubendren A. L. Selvarajan, Salah Al-Zubaidi, Samaher Mohammed Study on Solar Panel Cleaning Robot. IEEE International Conference on Automatic Control and Intelligent Systems (I2CACIS), 29 June, Selangor, Malaysia (2019) 